\title{
Los malos tratos y vejez: un enfoque psicosocial
}

\section{Ill treatment and ageing: a psychosocial approach}

\section{Mercedes TABUEÑA LAFARGA*}

Fecha de Recepción: 08-09-2006

Fecha de Aceptación: 30-11-2006

\section{RESUMEN}

Estamos ante una de las formas de violencia más oculta, se trata de la inflingida a las personas de edad avanzada, grupo de población sumamente vulnerable. Es un fenómeno silenciado, desconocido, incomprendido y escasamente detectado. Los profesionales conocen su existencia, no obstante, existen grandes dificultades para su abordaje. La realidad es que no se le presta la necesaria atención, puesto que a menudo es más fácil creer que no existen que haber de afrontar aquello que puede llegar a ser una realidad extremadamente impactante y sumamente compleja.

Los expertos auguran que el número de situaciones de malos tratos a los mayores irán en aumento a causa del progresivo envejecimiento de la población, de la esperanza de vida, del incremento de situaciones de dependencia fisica y psíquica y sobre todo por el mayor y mejor reconocimiento de los derechos de las personas mayores. No olvidemos los cambios sociales, culturales, los estereotipos negativos sobre el envejecimiento los cuales fomentan la discriminación por la edad (edadismo)

Todos estos factores nos van indicando la presencia de importantes transformaciones en nuestra sociedad las cuales es preciso abordarlas con una gran dosis de creatividad y celeridad Ante esta emergencia surgen cuestionamientos sobre las normas y las condiciones respecto a los cuidados familiares. Modificaciones en las pautas de las obligaciones de los parientes (el sentido de la obligación) que cada vez más va dejando de ser vigente. El cuidado a los ancianos no está claramente definido en normas sociales explicitas como lo esta para los menores.

Se pretende hacer una llamada de atención a los profesionales y de forma especifica a los psicólogos, educadores, trabajadores sociales y muchos otros, sobre la necesidad de sensibilizar e informar, puesto que su ámbito de acción es privilegiado para poder prevenir, detectar, diagnosticar e intervenir en estas situaciones.

\footnotetext{
* Treballadora social, Psicóloga, Máster en Gerontología Social/UB), Profesora titular de la Universitat de Barcelona, membre el Grup EIMA. ctabuena@ub.edu
} 


\title{
PALABRAS CLAVE
}

Malos tratos a personas mayores, Vejez, Abordaje integral.

\begin{abstract}
One of the most hidden forms of violence is the violence against older persons - a highly vulnerable population. It is a phenomenon that has long been silenced, misunderstood and hardly detected. Although professionals know this problem, great difficulties exist to address it. Actually, not much attention has been paid to this problem. Sometimes it is easier to deny events like these than to face them, even if they may become extremely shocking.

Experts foretell an increasing number of ill-treatment events inflicted to aged persons owing to the increasing ageing of the population, life expectancy, physical and psychological dependence and the acknowledgement of old people's rights. Social and cultural changes, along with negative stereotypes about ageing, favour age discrimination.

The aforementioned factors are an indication that important social changes are taking place that need to be addressed quickly and creatively. As a result, current standards and conditions concerning family care and patterns of family duties are questioned. Therefore, older persons care is not clearly specified in social regulations, as is the case with children.

This paper attempts to draw the attention of practitioners, especially psychologists, pedagogues, social workers, etc. about the importance of their role and the need that they get involved in prevention, detection, diagnosing and intervention to tackle this problem.
\end{abstract}

\section{KEY WORDS}

Ill-treatment in older persons, Ageing, Comprehensive approach. 


\section{INTRODUCCIÓN}

Nuestra sociedad se enfrenta a un fenómeno único en la historia de la humanidad, el envejecimiento de la población que nos aporta nuevas situaciones que debemos afrontar con celeridad y creatividad. Una de ellas es el abordaje de la violencia y maltrato a las personas de edad avanzada.

La constatación de la existencia de maltrato y negligencia en torno a las personas mayores es generalizada entre los profesionales, así como la gran dificultad que ofrece la detección de evidencias a través de pruebas empíricas sistemáticas.

Estamos inmersos en una cultura de la violencia y ésta se manifiesta en todos los ámbitos: comunitario, institucional y familiar, afectando especialmente a las personas más débiles y vulnerables. La violencia no entiende de cultura, de clases sociales, ni de género, ni raza, ni por supuesto de edad.

La sociedad española también evidencia su percepción sobre la posibilidad del maltrato a los ancianos como una realidad muy extendida entre nosotros.

El II Plan Nacional contra la violencia domestica (2001-2004), que consta de 58 medidas, 20 se refieren a la prevención y sensibilización, 17 a la asistencia e intervención social, 8 a la investigación y otras son legislativas y judiciales, pues bien en todo él no se hace referencia al ámbito del maltrato a personas mayores. Es un buen momento para introducir una visión holística del tema, no olvidando que también existen otros grupos de edad y de género, como son las personas mayores, que deben ser atendidas adecuadamente.

La violencia es una forma de agresión, es un impulso genético programado para la supervivencia. Lo que ocurre es que progresivamente este impulso ha sido domesticado y se ha pasado de un estado natural a un estado de derecho. No obstante, el grupo familiar ha escapado a esta transformación de la violencia. En nombre del respeto a la vida privada, la familia continúa siendo un tabú, las leyes y la sociedad no se atreven a intervenir en sus dinámicas de violencia.

Pero, no debemos olvidar que en las sociedades democráticas una de las formas de generar violencia es silenciarla y a la vez consentir que se mantengan modelos inadecuados. Generalmente la sociedad tiene una reacción de insolidaridad ante este tema por el hecho de minimizar sus consecuencias.

\section{ORIGEN DEL CONCEPTO DE MALTRATO A LAS PERSONAS MAYORES}

El maltrato a las personas mayores se describió por primera vez en el año 1975 en una carta publicada por G.R Burston en la revista The British Medical bajo el titulo "Granny battering" (abuela golpeada), seguida por un artículo de Robert N. Butter's titulado “¿Porqué sobrevivir? Ser anciano en América", donde se describe por primera vez el Síndrome de la anciana apaleada, para llegar al de "maltrato de personas mayores" en 1993 (Bennett y Kingston). Posteriormente, en Estados Unidos, el Congreso se preocupó por el tema a nivel político y social, más tarde fueron los investigadores y los profesionales quienes abordaron el tema.

En los inicios de la década de los ochenta, el interés y la preocupación por los malos tratos a las personas mayores ha ido extendiéndose por varios países industrializados como Estados Unidos, Japón, Australia, Canadá, China (HongKong), Noruega, Suecia y Argentina, 
India, Chile, Reino Unido y, Canadá, Gran Bretaña, Suecia, Noruega adquiriendo así el tema relevancia mundial, mediante artículos, encuestas y trabajos diversos. En la ultima década Francia destaca por su gran interés por intervenir en este tema tan emergente de los malos tratos a los ancianos.

El hecho de considerar de una forma distinta el concepto social de anciano o persona mayor hace dificultoso el hacer comparaciones entre los estudios y los países.

España destaca por su silencio y solo, de una forma muy tímida, desde el inicio del nuevo siglo, surge algún articulo, conferencia, mesas redondas o algún trabajo de investigación muy local y esporádico. El interés a escala politica es del todo insuficiente.

Uno de los aspectos más complejos y que más dificultad comporta es el de la falta de una definición universal y consensuada de los conceptos de abuso, negligencia, trato inadecuado, violencia y otros, ya que las diferentes definiciones que existen reflejan lo que se considera aceptable o no en materia de comportamiento interpersonal y comunitario en las diferentes sociedades.

Desde un punto de vista estratégico emergen dos prioridades:

- La de conocer las dimensiones reales del problema con la finalidad de poder elaborar modelos de intervención y saber cómo utilizar nuestros recursos limitados, así como para conocer indicadores sobre la etiología de los malos tratos.

- Por otro lado realizar un estudio de prevalencia e incidencia a escala nacional para favorecer la planificación general sobre el tema.
Hay tres elementos clave que explican esta complejidad (Tabueña 1999b).

- La falta de consenso universal sobre la definición de abuso y maltrato.

- El abuso y el maltrato efectuado a las personas mayores tiene menos relevancia que el efectuado a los menores y a las mujeres. Hay una gran invisibilidad hacia las personas de edad avanzada.

- Las características de las personas mayores y las de sus cuidadores no producen maltrato, pero en ocasiones coinciden con una situación de crisis y esto si que puede ocasionarlo.

Definir el maltrato es un ejercicio multifactorial que no puede tener una exactitud científica ya que se trata de una cuestión en la que los aspectos culturales, tradicionales, los valores y las normas de una sociedad adquieren una gran relevancia.

De las diversas definiciones que nos ofrece la literatura sobre el tema, nos inclinamos a aceptar la que corresponde a la Primera Conferencia Nacional de Consenso sobre el anciano maltratado en Almería el año1995 (Kessel et alt. 1996), donde se acordó la definición de maltrato a la persona mayor como:

"Cualquier acto u omisión que produzca daño, intencionado o no, que ocurra en el medio familiar, comunitario o institucional, que vulnere o ponga en peligro la integridad física, psíquica, así como el principio de autonomía o el resto de los derechos fundamentales del individuo, constatado objetivamente, 0 
percibido subjetivamente con independencia de la intencionalidad 0 no y del medio dónde suceda”.

Esta definición se ajusta a nuestro contexto y se centra con más especificidad a los malos tratos hacia los mayores. En la concepción de esta definición han participado profesionales de diversas disciplinas y ello queda reflejado en su zando en los estudios que se llevan a cabo, una clasificación en la que se incluye ocho tipos de maltrato que pueden padecer las personas mayores en los diferentes ámbitos, familiar, institucional y estructural o social.

Los tipos tienen un carácter genérico pero no son excluyentes y son las siguientes:

\begin{tabular}{|ll|}
\hline & Clasificación \\
1) Abuso Fisico & 5) Negligencia \\
2) Abuso Psicológico & 6) Autonegligencia \\
3) Abuso Sexual & 7) Abandono \\
4) Abuso Económico & 8) Vulneración de Derechos \\
- Dos Sindromes: & \\
- Síndrome de la Abuela Esclava (SAE) \\
- Sindrome de Diógenes(SD)
\end{tabular}

redactado. Destaca la intencionalidad o no del acto, aspecto relevante para el diagnostico y posterior intervención. Se detallan también las diversas tipologias de los malos tratos e incorpora la participación de la propia persona víctima de maltrato haciéndola asi protagonista de su propio acontecer.

Es importante mencionar que el maltrato puede tener lugar en cualquier contexto, es decir puede darse en el ámbito familiar, el institucional (centros de dia, hospitales, residencias), y en lugares públicos que pueden ser considerados como seguros. Asimismo, el maltrato puede ser estructural o social (acoso inmobiliario y otros).

\section{TIPOS DE LOS MALOS TRATOS A LAS PERSONAS MAYORES}

En estos momentos y teniendo en cuenta nuestro contexto, se esta utili-

\section{1.- Abuso físico}

Es la utilización de la fuerza física la cual puede ocasionar heridas corporales, dolor físico y un deterioro en la salud.

Se considera entre otras el uso inadecuado de fármacos, la alimentación forzada, los confinamientos y restricciones mediante medidas no adecuadas. El castigo físico de cualquier tipo. La privación de alimentos sólidos y líquidos.

\section{2.- Abuso psicológico}

Consiste en ocasionar dolor, angustia, pánico o terror mediante actos verbales 0 no verbales, como las amenazas, la humillación, los insultos, la instigación y la intimidación. Es muy dificil de determinar debido a su gran carga de subjetividad que comportan los sintomas del mismo, pero pueden ser sumamente graves. 
Se puede detectar por: un estado de agitación en el plano emocional; actitud más distante de lo habitual o por la propia declaración de la persona objeto del mismo.

\section{3.-Abuso sexual}

Se produce cuando hay un contacto sexual con una persona anciana sin tener el consentimiento, los atentados contra el pudor como los tocamientos y la pornografía. Es la violación, la sodomía, el desnudo forzado, la fotografía sexual explícita.

\section{4.- Explotación financiera 0 abuso económico}

Se trata de la utilización abusiva o ilegal de los bienes e inmuebles propiedad de la persona mayor.

En la propia comunidad también las personas mayores son objeto de este tipo de explotación mediante practicas de ventas fraudulentas y engañosas, estafas coyunturales, manipulación de documentos para fines totalmente ajenos a la voluntad de las personas (subastas y otros).

\section{5.- La negligencia}

Es un comportamiento nocivo, intencionado o no, por parte de una persona que esta obligada a cuidar a la persona anciana. Segun el National Center Elder Abuse, se entiende por negligencia, el rechazo o la omisión de proporcionar a la persona anciana las necesidades de la vida, como el agua, los alimentos, el vestir, la vivienda, la higiene personal, la medicación, la seguridad personal y los otros bienes esenciales. Puede ser activa o pasiva. La activa se refiere a la falta de cuidados necesarios por parte del cuidador, de una forma consciente. La pasiva se centra en el olvido y el abandono.

\section{6.- La autonegligencia}

Es el comportamiento de una persona mayor que amenaza la propia vida o su salud. Se excluye en esta tipología aquellas personas mayores competentes (con plena capacidad mental), que optan por decisión propia a cometer actos que amenacen su seguridad.

Es un concepto aplicable a una amplia gama de comportamientos y no sólo en situaciones extremas de falta de recursos o habilidades para llevar a cabo la actividades necesarias que garantizan la propia salud o bienestar. Existe un debate abierto en si debe ser o no considerado maltrato en cuanto no existe una persona que lo ocasione.

\section{7.- Abandono}

Se considera abandono cuando una persona, que está encargada de prestar cuidados y atención a una persona mayor o de asegurar su atención física, la abandona. Se trata de la claudicación total.

\section{8.- La vulneración de los derechos}

Incluye los derechos elementales que no están contemplados en el resto de tipologias puesto que en todos los tipos de malos tratos a las personas mayores se da implícitamente una vulneraciốn de derechos.

Consiste pues en la agresión, privación o no reconocimiento de los derechos fundamentales como: dignidad y respeto; intimidad y confidencialidad; participa- 
ción; libertad de elección y derecho a ser cuidado.

En nuestro país se observa un avance en la regulación y potenciación de algunos de estos derechos, un buen ejemplo lo tenemos en las leyes implementadas en las comunidades autónomas relativas a las Voluntades Anticipadas (Testamento Vital). Documento en el que una persona manifiesta libremente las instrucciones a tener en cuenta cuando se encuentre en su situación en la que no pueda ya expresar su voluntad. Otro ejemplo es la posibilidad de llevar a cabo la Autotutela, mediante el cual la persona puede decidir libremente quien será su tutor legal en caso de ser declarada incapacitada legalmente.

A pesar del intento por clasificar los malos tratos en categorías surgen aspectos que no pueden ser ubicados con precisión y necesitan de una flexibilidad en función de las características de la situación, de la interpretación de los profesionales y también de la subjetividad de la persona que lo padece.

Las controversias suelen aparecer también por los solapamientos de las diferentes tipologias y conceptos. Veamos a continuación algunos ejemplos:

a. ¿El abuso sexual se incluye en los físicos? Hay autores que el abuso sexual lo incluyen en la categoria de los abusos físicos. No obstante, podemos observar que otros estudiosos consideran que este tipo de abuso tiene tanta importancia en si mismo que se merece una tipologia especifica.

b. ¿El encarnizamiento terapéutico es una vulneración de derechos, a la vez es un maltrato físico o debe considerarse como una tipología propia? c. La inframedicación o sobremedicación se incluye en el abuso psicológico, lo que ocurre es que también puede contemplarse como una vulneración de derechos y asimismo como un abuso físico. La cuestión es de si debe o no considerarse una tipologia propia.

d. El aislamiento puede ser una autonegligencia (Síndrome de Diógenes) o una negligencia, a la vez una vulneración de derechos si se le niega la participación y también un abuso psicológico.

e. Parecida controversia produce la falta de alimento que puede ser contemplada como una negligencia, una autonegligencia, un abandono y a la vez un abuso físico.

Mencionamos a continuación dos sindromes que están tomando relevancia debido a la cantidad de personas que se están detectando mediante la labor de los profesionales de primera linea, desde sus servicios de atención primaria, concretamente, médicos, psicólogos y trabajadores sociales.

\section{EL SÍNDROME DE LA ABUELA ESCLAVA}

El Sindrome de la Abuela Esclava (SAE) se puede definir como una enfermedad, grave, potencialmente mortal, que afecta a mujeres mayores con responsabilidades directas de ama de casa, voluntariamente asumidas, y con agrado, durante muchos años. Suelen disfrutar con los nietos, raramente se quejan aunque a menudo estén agotadas Algunas mueren en "acto de servicio", otras sufren en silencio, llevan una carga con la que ya no pueden, pero resisten por miedo a perder el reconocimiento de los suyos. Fue descrito por el 
cardiólogo Dr. Antonio Guijarro en el año 2001 como consecuencia de una sintesis o abstracción de circunstancias comunes en pacientes atendidas durante décadas.

Este síndrome figura en la bibliografia básica del Instituto de Investigación y Capacitación de las Naciones Unidas para la promoción de la mujer como una tipología más de maltrato. El INSTRAW organismo de la ONU, ha reconocido el interés social del SAE y lo distingue como una de las más relevantes formas mundiales referidas al abuso de las mujeres mayores.

El SAE se produce por un agotamiento excesivo o sobreesfuerzo físico y emocional crónicos. El estrés se refleja por el agobio que nace de esa obligación, con responsabilidad directa de cumplir simultáneamente varias tareas con eficacia, puntualidad y acierto.

No existen muchos estudios al respecto, no obstante, destacamos uno que por sus resultados nos parece relevante. Un reciente estudio norteamericano demuestra que las abuelas anglosajonas no son ajenas a este problema sanitario y social. Lee, S. (2003) y colaboradores, de la Escuela de Salud Pública de Harvard, en Boston, han publicado recientemente, los resultados de un estudio prospectivo, realizado con 54,412 mujeres de 46-71 años. En el mismo comprueban que el cuidado de los nietos durante 9 o más horas semanales aumenta el riesgo de infarto de miocardio y otros eventos coronarios en un 55 por ciento. El cuidado de hijos propios tiene menos influencia patológica. Los autores apuntan al conflicto del papel o función de abuela y al estrés, como posibles factores determinantes de este fenómeno. Es un exponente de medicina basada en la evidencia, que supone un respaldo "científico convencional".

\section{EL SÍNDROME DE DIÓGENES}

Se trata de una conducta de aislamiento comunicacional, ruptura de las relaciones sociales, negligencia de las necesidades básicas como la higiene, alimentación, cuidados de salud, vestido, reclusión domiciliaria, rechazo de las ayudas y negación de la situación patológica, que se presenta habitualmente en ancianos solitarios.

La denominación se debe a Clark et al. (1975) y se basa en el estilo de vida misantrópico y solitario del conocido filosofo griego.

Se trata de un Sindrome que se produce con más frecuencia en ancianos como consecuencia de la interrelación de tres tipos de factores:

a) Rasgos de personalidad previos, que implican tendencia al aislamiento, dificultades de adaptación social, rechazo de las relaciones humanas, misantropía (persona que se aleja del trato con la gente), etc.

b) Factores estresantes propios de la edad tardía; dificultades económicas, muertes familiares, rechazo familiar, marginación social y otras.

c) La soledad que, inicialmente puede surgir condicionada por las circunstancias y que posteriormente es buscada y deseada voluntariamente.

Tratar estos casos es una tarea sumamente compleja y difícil, no obstante, una vez conocido debe ser atendido en una Unidad de Geriatría para poder abordar todos los trastornos médicos, psicológicos y sociales. El trabajo interdisciplinar es fundamental puesto que 
intervienen muchos factores de personalidad y ambientales. En el plan de acción se debe considerar el hecho de evitar el regreso del enfermo a sus condiciones previas de vida. En algunos casos es preciso tratar la patología psiquiátrica asociada como depresión o delirios crónicos. Es fundamental la coordinación entre los servicios de salud y los de servicios sociales para hacer un seguimiento y una evaluación de los casos.

\section{LA DETECCIÓN DE LOS MALOS TRATOS A LAS PERSONAS MAYORES}

Nos encontramos ante una tarea, la detección difícil, a menudo complicada por la negación que suelen hacer tanto la persona mayor como también la persona que comete los malos tratos.

Detectar los malos tratos depende también de la concienciación, del conocimiento y de la comprensión tanto social o colectiva como individual que se tiene del problema. Estas premisas determinan aquello que pude ser considerado como maltrato a una persona mayor, aquello que se reconoce y por tanto, clasificado según unos criterios aceptados y hallados en la literatura existente.

A pesar de ser reconocido como un problema de salud de primer orden (OMS,2002) y que afecta a muchas personas en el mundo, en cifras absolutas y relativas, la detección es compleja, de tal manera que se considera que por cada caso detectado y documentado hay cinco que no salen a la luz.

El porqué de la falta de detección obedece a múltiples causas. Así encontramos que, la mayoria de los abusos se comenten en lugares, de puertas a dentro, incluso en las instituciones, y por lo tanto se abren con mucha reticencia al escrutinio público. Conseguir que todo aquello que sucede en la esfera privada sea un tema de preocupación pública no ha sido fácil en ninguna de las formas de mal trato, nos referimos a todo aquello que ha tenido referencia a los menores y a la mujer, pero en el caso de las personas mayores, añadimos el factor del edadismo estructural y la ambivalencia respecto a los cambios de valores que se plantean por parte de la familia y por parte de la comunidad en cuanto a la clase y forma de cuidados que deben tener las personas mayores dependientes.

La detección está limitada por las normas y los valores culturales, los estereotipos negativos, el edadismo, las falsas creencias como pensar que lo que ocurre es siempre culpa de la edad, y por lo tanto no es susceptible de tratamiento.

Los malos tratos a las personas mayores toman formas particulares que exigen de los organismos y de los profesionales formulas muy abiertas e imaginativas para poder llegar a captarlos. Las personas mayores no suelen presentar denuncia alguna.

\section{¿ANTE QUÉ DEBEMOS SOSPECHAR?}

He aquí la relación de algunas señales o signos de alerta, precoces de maltrato, recogidos mediante las aportaciones de la literatura existente y de la observación de nuestro propio trabajo, que pueden ser útiles a los profesionales para ayudarles a intuir que alguna cosa está pasando ante una situación concreta. Los signos pueden ser:

- La demora en solicitar asistencia social o médica. Suele haber un intervalo prolongado de tiempo 
entre el hecho concreto y la visita al profesional.

- El anciano maltratado es llevado al centro de salud o de servicios sociales por otra persona que no sea el cuidador habitual.

- Narraciones o relatos contradictorios o inverosímiles respecto el cómo ocurrió el incidente entre la persona cuidadora y la persona mayor.

- Falta de comunicación de la víctima con el profesional, social o médico, cuando el cuidador está presente. Resistencia y negativa del cuidador a dejar solo al anciano con los profesionales.

- Desnutrición, deshidratación, caídas reiteradas, todo ello sin motivo aparente.

- Actitud de retraimiento, miedo, inquietud de la persona mayor.

- Alteración del estado de ánimo, ansiedad, confusión, insomnio, inapetencia, depresión.

- Vivienda que presenta unas condiciones higiénicas inaceptables y es inadecuada para poder vivir en ella.

- Historia previa de episodios sospechosos de malos tratos.

En nuestra sociedad se producen situaciones de abuso y existe una especie de barrera para reconocer los malos tratos, ésta actitud repercute en las familias, en las instituciones, en los individuos que las componen y en última instancia en las organizaciones públicas del país. Este es, sin lugar a dudas el gran déficit que tiene la detección de las víctimas.

\section{EL SILENCIO CÓMPLICE DE LOS MALOS TRATOS}

Considerando que las personas mayores no suelen denunciar sus situaciones de maltrato postulamos que el silencio (no solamente el de las víctimas sino también el de los profesionales y el de la sociedad en general) es cómplice de los malos tratos. Existe así, un círculo de silencio, de ignorancia y de vulnerabilidad

Los profesionales debemos comprender el silencio de las víctimas a fin de favorecer mejor la comunicación con ellas, teniendo en cuenta la dificil relación que se establece con el entorno. Se debe evitar el incremento de su inseguridad y el agravamiento de sus condiciones. En los procesos de detección, requerir la implicación y el testimonio de los testigos y cuidadores es a menudo fundamental y necesario. Estas personas también viven y comparten sentimientos de inseguridad unidas al contexto de la víctima.

Analicemos algunas de las dinámicas relacionales entre la victima y su entorno

\section{A nivel de temores de las victimas}

Las personas mayores generalmente sienten unos temores que se sitúan en el exterior de la persona, son realidades percibidas provenientes del entorno. Las víctimas piensan que serán objeto de:

- Sufrir represalias.

- Ser abandonadas, ser ingresadas en un establecimiento residencial 0 miedo a perder la plaza que ocupan,

- Ser causa de un escándalo y ser el origen de un conflicto en la familia.

- Miedo a perder las relaciones significativas (nietos...) 
Así de esta forma, se puede encontrar que las personas mayores víctimas de malos tratos se manifiestan mediante indicadores no específicos como: fugas, agitación, claudicación (autonegligencia), no ingesta de alimentos, depresión.

\section{A nivel de percepción de las propias victimas}

Las percepciones son elementos cognitivos y/o emotivos que organizan la experiencia y la forma cómo evalúan las víctimas su situación. He aquí algunas manifestaciones:

- Ellas no se dan cuenta de la gravedad de la situación.

- Excusan y justifican los comportamientos abusivos.

- Ignoran las posibilidades de ayuda y los recursos.

- Se sienten culpables e impotentes de su situación de dependencia y por lo tanto de la necesidad de precisar ayuda.

- Creen poder resolver por si solas el problema.

- Existe una indefensión aprendida. Se percibe un sentimiento de ser una carga para la familia y para el entorno. En ocasiones se sienten culpables de los comportamientos de maltrato recibido (alguna cosa habré hecho mal...)

\section{A nivel de actitudes del entorno de la victima}

La actitud del entorno es la reacción previsible del medio ambiente en térmi- nos de resistencia para reconocer la realidad de los malos tratos. ¿Por qué?

- Negación del problema por el entorno.

- Minimización del incidente en el origen de la queja o denuncia.

- Temor a los conflictos y a las represalias.

- Sufrir una presión para la conformidad.

- Desconocimiento de la existencia de recursos de soporte.

- Creencia de la obligación de confidencialidad.

\section{A nivel de la revelación de la victima} ser:

Los sentimientos que surgen suelen

- La débil probabilidad que tiene la victima de ser creída.

- El sentido que la víctima da a la situación de abuso.

- La capacidad limitada de comunicar claramente los detalles de la situación-problema.

- La ausencia de una persona de confianza en el entorno de la víctima.

- La importancia de la relación afectiva con el abusador

\section{El silencio de los cuidadores}

Cuando los profesionales de cualquier categoría laboral, que ejercen su activi- 
dad en una institución dedicada a personas mayores perciben algún tipo de maltrato, por ejemplo, problemas de desnutrición, de abuso en la contención física o farmacológica, de infantilización u otro tipo de trato inadecuado, raros son aquellos que toman el riesgo de enfrentarse ante quien corresponda la responsabilidad del centro (los cuidadores 0 dirección).

Muchos profesionales cierran los ojos para no ver "historias". Lo que cuenta es que el servicio continúe y que no existan quejas ni de los residentes ni de las familias. Lo que importa es la apariencia, aquello que se ve. El suelo debe estar limpio y brillante, las mesas bien puestas y las camas bien hechas. Poco importa si para obtener todo esto el personal ha realizado el cuidado y limpieza intima en un tiempo récord, nadie lo sabrá. Los residentes no dirán nada porque no podrán o por temor a represalias. Una institución bien arreglada no garantiza que en ella se viva con calidad y percibiendo un buen trato.

El silencio en las instituciones puede estar fundamentado en que:

- La imagen es un valor importante a la vez que un recurso financiero.

- La discreción es una regla implícita o explícita en la producción y la distribución de bienes y de servicios: el deber de reserva y de discreción profesional equivale a la obligación de guardar silencio respecto aspectos negativos que pueden dañar la imagen del centro.

El silencio de los cuidadores puede fundamentarse en:

- Actitud eficaz para auto protegerse. Un conflicto no interesa.
- La ropa sucia se lava en casa. No se debe ensuciar la imagen de la casa.

- No se rompe la rama de la cual dependemos.

- Los procedimientos de una denuncia son complejos, largos y con un final desconocido; en cambio el reglamento interior del centro dispone de un procedimiento habitual.

\section{El silencio de las familias}

Normalmente ocurre que las familias opinan que es impensable que, el padre o la madre alojado en una institución, que ellos mismos hayan contribuido a buscar y decidir, pueda afrontar peligro de sufrir algún tipo de maltrato. Las visitas suelen ser muy rutinarias, tanto en el día como en la hora e investigan poco acerca de los cuidados y atenciones personales que reciben, tales como saber que tipo de medicación y con que frecuencia la toman o pedir el contrato 0 expediente asistencial para ver las anotaciones realizadas. Recordemos al respecto que en el expediente deben constar todos aquellos aspectos de tratamiento, el tipo y el momento de aplicar una contención ya sea física o farmacológica.

Por otro lado, es muy dificil encontrar un centro y una vez lograda una plaza el hecho de indagar y llegar a la conclusión de trato deficiente ocasionaria el problema de llevar a la persona de nuevo a casa y reiniciar la búsqueda de otro centro. De tal forma sería necesario revivir la crisis familiar producida por el ingreso en una institución, que se quiere obviar.

\section{El silencio de las administraciones}

Algunas politicas y valores sociales pueden influir sobre la probabilidad de 
que se produzcan malos tratos y también que se reduzca el potencial, tanto de detección como de prevención.

También es una realidad constatable, en muchas ocasiones, el silencio de los organismos públicos estatales, autonómicos y municipales con responsabilidades para intervenir en situaciones de violencia, abuso y malos tratos dirigidos a los ancianos. Por este motivo se puede afirmar su complicidad y participación en mantener cuidados inadecuados y el maltrato a la población anciana expuesta a estas situaciones.

Numerosas organizaciones alzan su voz y recomiendan que se definan acciones dirigidas a la prevención, detección y tratamiento de los malos tratos a las personas mayores (OMS, Asamblea Mundial sobre el Envejecimiento, Declaración de Almería y otros), a las que en demasiadas ocasiones se les hace caso omiso.

Es necesario poder identificar los riesgos previsibles para no exponer inútilmente a las personas mayores a un riesgo de padecer una situación de maltrato.

\section{CONSECUENCIAS PSICOLÓGICAS, SOCIALES Y DE SALUD DE LOS MALOS TRATOS A LAS PERSONAS MAYORES}

El proceso de envejecimiento entraña la reducción de la capacidad de recuperación, por lo que las personas de edad que han sido víctimas de malos tratos pueden no llegar a recobrarse nunca del todo, física o emocionalmente, de la experiencia sufrida.

La mayor parte de la literatura sobre los malos tratos a las personas mayores está enfocada a cómo poder detectarlos y la forma más idónea de intervenir en ellos. No obstante, existen autores que han dedicado su reflexión a teorizar y buscar datos sobre el efecto de los malos tratos en las personas que los padecen.

Es relativamente fácil establecer una relación directa entre una lesión física y sus secuelas posteriores, avaladas por el seguimiento médico, pero es mucho más complejo establecer esta relación cuando se trata de un daño psicológico. En este caso, se plantea un modelo ecológico explicativo, en el que la personalidad de la propia victima, las relaciones con el entorno y las experiencias sociales previas son los parámetros a tener en cuenta para poder efectuar una evaluación.

En muchas ocasiones, en los informes no aparece la descripción de las consecuencias que han supuesto los abusos económicos, las humillaciones o las agresiones sexuales, es decir, el impacto que los distintos tipos de malos tratos hayan podido causar a la persona mayor, sino que solamente se suele detallar la consecuencia más grave a titulo de resumen global. Las victimas pueden sufrir multitud de secuelas mucho más dificiles de apreciar, pero igualmente graves a corto y largo plazo. A pesar de todo, se apunta que la violencia y los malos tratos a los mayores, tanto en el medio familiar como institucional, causan morbidad y mortalidad importantes. Lachs et al. (1998), afirman que el hecho de sufrir malos tratos acorta la vida.

Si nos referimos a los trastornos psicológicos asociados a los malos tratos, podemos relacionar la ansiedad, la depresión y la baja autoestima entre otros, los cuales pueden producir disfunciones físicas en diversas áreas de la persona y afectar al descanso, producir mareos y dolor de cabeza o trastornos de la alimentación. También pueden producir disfunciones psíquicas como angustia, irritabilidad, reducción de la capaci- 
dad de memoria y de la expresión, aislamiento social, alteración de la percepción y de la valoración de lo que sucede y tentativas autodestructivas como el suicidio.

Se cita también el estrés postraumático, el cual aparece en muchas de las víctimas de violencia o de maltrato, las cuales suelen sentirse responsables de su situación. Tienen sentimientos de vergüenza y tienden a minimizar los efectos, por lo que no se conceden el derecho a pedir ayuda.

A titulo de ejemplo exponemos que la hipotermia y la hipertermia también son causas potenciales que precipitan la muerte de las personas mayores, especialmente de las que padecen una discapacidad y que en muchos casos, con un buen seguimiento podría ser evitada. Respecto al estado nutricional y de hidratación, son también factores importantes para la defensa del organismo hacia posibles enfermedades y ante la respuesta inmunológica. La desnutrición favorece la aparición de úlceras de decúbito en los pacientes encamados, de la misma forma que la falta de higiene y la inmovilización postural.

Son desconocidos los efectos de los abusos sexuales en los hombres, por el contrario sí se conocen algunos de los efectos en las mujeres, las cuales desarrollan conductas fóbicas y de evitación, así como miedo, ansiedad, estrés postraumático, desintegración social respecto de sus relaciones afectivas y de ocio, entre otras.

La Organización Mundial de la Salud (OMS - Informe Violencia y Salud, 2002) ha calificado a la violencia como un problema de salud pública y de derechos humanos en todo el mundo y, a pesar de que no hay estudios específicos sobre el suicidio en personas mayores, las cifras globales de suicidio en este grupo de edad son tres veces superiores a las de otros grupos.

Estas, entre otras consecuencias, son las que ponen en evidencia la gravedad del tema de los malos tratos a las personas de edad avanzada y también ponen de manifiesto la necesidad de aplicar actuaciones que vayan dirigidas, bien a la raíz del problema mediante acciones preventivas, bien a las fases iniciales del problema para una detección precoz o bien a eficaces intervenciones multidisciplinares acompañadas de los recursos idóneos y necesarios.

\section{LA INTERVENCIÓN}

Toda intervención debe estar regida por unos principios fundamentales que permiten llevar a cabo una estrategia que tiene como finalidad prevenir y evitar los malos tratos, al mismo tiempo que se preservan los derechos y los intereses de la persona mayor y sus relaciones personales. Estos principios fundamentales son:

\section{A. Las personas tienen derecho a:}

- Tener las necesidades básicas cubiertas (alimento, vestido, vivienda...).

- Estar protegidas contra los malos tratos.

- A ejercer su autodeterminación y poder conducir su vida como crean conveniente, siempre que no pongan en peligro o vulneren algún derecho a una tercera persona.

- Tomar parte en las decisiones que le afecten, teniendo en cuenta sus capacidades.

- Rehusar ayudas o prestaciones. 
B. Cada caso debe ser analizado individualmente para poder determinar los deseos de la persona mayor y el grado de intervención que demanda.

- La intervención ha de ser proporcional a la medida del riesgo al cual está expuesta la persona mayor.

- Los perjuicios y convicciones de los profesionales pueden reflejarse en las decisiones que se tomen para llevar a cabo la intervención. Cada profesional ha de reconocer sus responsabilidades y evitar privilegiar o castigar comportamientos.

C. La intervención tiene como finalidad acabar con el maltrato y por tanto proteger a la víctima, pero también, la de mejorar la percepción del comportamiento propio, para lo cual se precisa de empatía.

D. Las intervenciones deben aplicarse con las medidas menos perturbadoras y restrictivas posibles para la persona mayor. Se ha de elaborar un método de participación voluntaria de todas las personas implicadas, teniendo en cuenta sus personalidades y circunstancias, puesto que de otra forma se pueden generar reacciones negativas y como consecuencia, que la persona mayor rehúse la ayuda. Se han de clarificar las demandas de la víctima para determinar cual debe ser la estrategia de trabajo del equipo de intervención.

E. Se ha de comunicar al Ministerio Fiscal o al Juzgado e intervenir obligatoriamente en caso de que:

- Se trate de una persona mayor presuntamente incapacitada para tomar decisiones.
- Exista una infracción del código penal.

- La persona mayor represente un peligro para una tercera persona.

- Se ha de informar al Juzgado en el caso de que existan agresiones, amenazas, robos y abandono. En los otros supuestos las personas mayores pueden rehusar cualquier ayuda 0 intervención.

F. Mantener la confidencialidad respecto a la información de las situaciones de maltrato. Todos los profesionales que intervienen en el caso, psicólogos, trabajadores sociales, médicos, abogados, se ven obligados a mantener confidencialidad y a obtener el permiso de la persona mayor para pasar información de un profesional a otro, a excepción de los casos en los que hay obligatoriedad de denunciar o comunicar.

G. Prestar el adecuado nivel de intervención.

Actualmente, el abordaje de una situación de maltrato a una persona mayor se hace, generalmente, desde los servicios sociales o servicios de salud de atención primaria, actuando sobre situaciones de riesgo (prevención primaria), sobre situaciones confirmadas de maltrato (prevención secundaria), o bien sobre las consecuencias del maltrato (prevención terciaria).

Ante situaciones tan complejas y multifactoriales como son los maltratos a las personas mayores, su intervención debe ser necesariamente diseñada y efectuada por profesionales de diversas disciplinas.

Para poder intervenir integralmente en estas situaciones de maltrato, es con- 
veniente construir un equipo interdisciplinar (reagrupamiento de miembros de personal de un solo organismo o de distintos organismos). Algunas de las metas del equipo serán:

- Configurar el espacio en el que sean presentados los casos para formular diagnósticos y planes de intervención.

- Asegurar que son aplicados los protocolos de intervención.

- Atribuir la responsabilidad de las tareas a los miembros del equipo, así como dar soporte y sugerir actuaciones.

- Si es necesario, canalizar casos a otros equipos para la intervención apropiada.

- Evaluar la eficacia de las intervenciones y colaborar en la toma de decisiones relativas a los diferentes planes de acción.

Como consideración importante destacamos que la violencia es una lacra social contra la cual se debe enfrentar toda la ciudadanía, en especial las instituciones y sus profesionales. Por este motivo hay que tener muy en cuenta las reformas legislativas introducidas actualmente con la Ley 27/2003 de 31 de julio, reguladora de la orden de protección de las víctimas de la violencia doméstica y la Ley orgánica 11/2002 de 29 de septiembre, por la que se modifican determinados artículos del código penal. Asimismo, la ley regula que toda persona que, por razón de su cargo, tenga noticia o conocimiento de cualquier delito público (y la violencia doméstica lo es) tiene la obligación de comunicarlo inmediatamente al Ministerio Fiscal o al Juzgado.

\section{PROPUESTA DE ALGORITMO DE INTERVENCIÓN}

La actuación frente a un caso de maltrato a una persona mayor, se considera adecuado estratificarla en diferentes niveles:

a) El grado de severidad de la situación.

b) La capacidad de la persona mayor para tomar decisiones.

c) La aceptación o no de la intervención por parte de la víctima, es decir la accesibilidad.

Cada nivel es determinante para elaborar la estrategia de la intervención.

En tanto que también fenómeno social y estructural, el problema de los malos tratos a las personas mayores ha de ser abordado desde el conjunto de la sociedad y especialmente debe ser liderado y coordinado por las administraciones públicas.

\section{Conclusión}

Ante la aparición de nuevas necesidades en nuestra sociedad, como es el abordaje de los malos tratos dirigidos a las personas mayores (nuevas formas de exclusión social), se considera necesario reformar algunos aspectos como:

- Mejorar la coordinación entre las distintas administraciones y actuar conjuntamente en bien de las personas y de las situaciones, al margen de los intereses politicos del momento.

- Potenciar la organización de los servicios sociales y de salud, mediante nuevas estrategias como pueden ser 


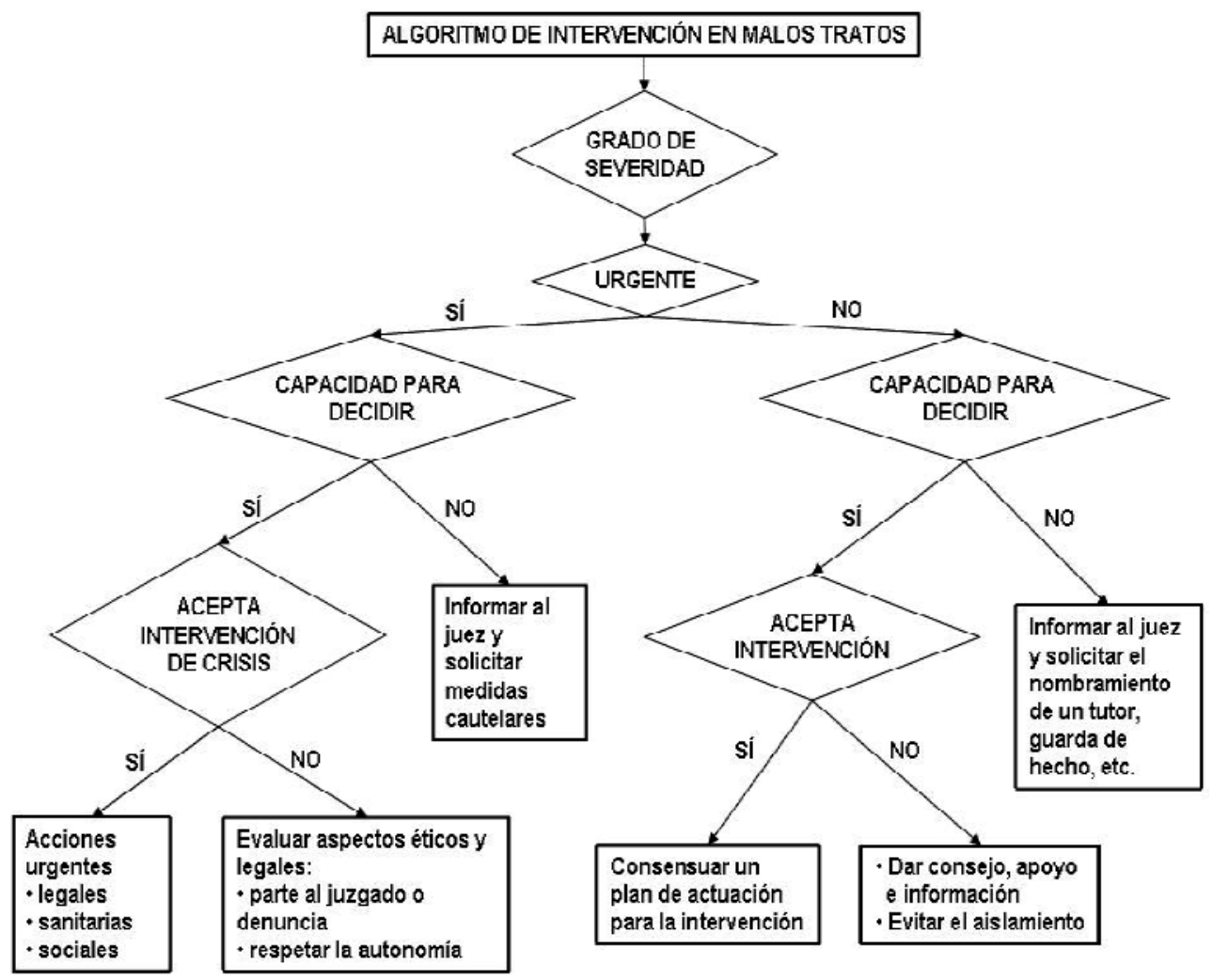

Fuente: Equipo EIMA de Barcelona (2004)

la transversalidad, el trabajo en red, dinámicas participativas, calidad de los servicios, coproducción de servicios, servicios personalizados y competitivos, entre otras. Todas ellas han de centrarse en una atención integral.

- Replantear la función y la formación de profesionales como el trabajador social y el psicólogo, entre otros, que tan importantes han sido y continúan siendo, en el transcurrir de los servicios sociales, considerando el resurgir de nuevas profesiones como, los mediadores, los integradores sociales y los animadores socioculturales, entre otros.
- Adaptarnos al nuevo perfil de usuarios de los servicios sociales, tanto en número como en características, mucho más informados de sus derechos y deberes, con más capacidad de crítica y con demandas mucho más estructuradas. Pensar en la generación de usuarios de clase media que no están necesitados como para acogerse a los criterios tan restrictivos de los servicios sociales públicos ni con tanta suficiencia económica, como para poder costear los servicios sociales privados.

- Por último destacar el gran debate, todavía pendiente, acerca de las situaciones de dependencia, el 
cómo, quién y cuándo debe protegerse a las personas mayores víctimas de esta situación, a pesar del libro blanco de la dependencia y de la futura ley de dependencia.
Para evitar que las personas mayores sean víctimas de maltrato es absolutamente necesario incidir en la concienciación social. El camino es largo pero ya estamos dado los primeros pasos.

\section{BIBLIOGRAFÍA}

Burston, G.R. (1975)."Granny battering”. The British Medical Journal, 3:592-596.

Coma, M., Muñoz, J., Orfila, F. y Tabueña, M. (2005). Los malos tratos a los ancianos. Barcelona: Mason.

Clark, A., Mankikar, G., y Gray, I. (1975). Diogenes Syndrome. Lancet, 15, 366-368.

Equipo Investigación Maltrato Ancianos (EIMA) 2002. Barcelona

Kessel, H., Marin, M., Maturana, N., Castañeda, L., Pageo, M., y Larrión, J.L. (1996). Primera Conferencia Nacional de Consenso sobre el anciano maltratado. Revista Española de Geriatría y Gerontología, 31 (6), 367-372.

Guijarro, A. (2001). El Sindrome de la Abuela Esclava Pandemia del Siglo XXI. Investigación Clinica, 4(4), 407-410.
Lee, S. (2003). Caring for grandchildren increases women's heart disease risk. American Journal of Public Health, 93 (11),1939-44.

Marin, N., Delgado, M., Aguilar, JL., Martinez, MA., Diez, A. y Soto, JA. (1991). Sindrome de maltrato y abuso en el anciano. Revista Española de Geriatria y Gerontología, 26 (1),40-46.

Organización Mundial de la Salud. (2002). Informe Violencia y Salud. Ginebra: OMS.

Ruiz, A., Altet, J., Porta, N., Duaso, P., Coma. M., Requesens, N. (2001). Violencia doméstica: prevalencia de sospecha de maltrato a ancianos. Atención Primaria 27(5), 331-334.

Tabueña, M. (1999b). Activitats preventives per a la gent gran. En Llibre Blanc. Barcelona: Generalitat de Catalunya. Departament de Sanitat i Seguretat Social. 